\title{
MiR-34c downregulation leads to SOX4 overexpression and cisplatin resistance in nasopharyngeal carcinoma
}

Pierre-Antoine Bissey ${ }^{1}$, Mona Teng ${ }^{2}$, Jacqueline H. Law ${ }^{2}$, Wei Shi', Jeff P. Bruce', Valentin Petit ${ }^{3}$, Sai W. Tsao ${ }^{4}$, Kenneth W. Yip ${ }^{1}$ and Fei-Fei Liu ${ }^{1,2,5,6^{*}}$ (i)

\begin{abstract}
Background: A major cause of disease-related death in nasopharyngeal carcinoma (NPC) is the development of distant metastasis (DM) despite combination chemoradiotherapy treatment. We previously identified and validated a four microRNA (miRNA) signature that is prognostic for DM. In this study, characterization of a key component of this signature, miR-34c, revealed its role in chemotherapy resistance.

Methods: Two hundred forty-six NPC patient biopsy samples were subject to comprehensive miRNA profiling and immunohistochemistry (IHC). Two human normal nasopharyngeal cell lines (immortalized; NP69 and NP460), as well as the NPC cell line C666-1, were used for miR-34c gain-of-function and loss-of-function experiments. Signaling pathways were assessed using quantitative real-time PCR (qRT-PCR) and Western blot. Cell viability was measured using the ATPlite assay.

Results: MiR-34c was downregulated in NPC patient samples, and confirmed in vitro to directly target SOX4, a master regulator of epithelial-to-mesenchymal transition (EMT). MiR-34c downregulation triggered EMT-

representative changes in NP69 and NP460 whereby Snail, ZEB1, CDH2, and SOX2 were upregulated, while Claudin1 and $\mathrm{CDH} 1$ were downregulated. Phenotypically, inhibition of miR-34c led to cisplatin resistance, whereas miR-34c over-expression sensitized NPC cells to cisplatin. TGF $\beta 1$ decreased miR-34C and increased SOX4 expression in vitro. The TGF $\beta$ receptor 1 inhibitor SB431542 reduced SOX4 expression and increased cisplatin sensitivity. Finally, IHC revealed that lower SOX4 expression was associated with improved overall survival in chemotherapy-treated NPC patients.
\end{abstract}

Conclusion: miR-34c is downregulated in NPC. Repression of miR-34c was shown to increase SOX4 expression, which leads to cisplatin resistance, while TGF $\beta 1$ was found to repress miR-34c expression. Taken together, our study demonstrates that inhibition of the TGF $\beta 1$ pathway could be a strategy to restore cisplatin sensitivity in NPC.

Keywords: miR-34c, SOX4, TGFß1, EMT, Nasopharyngeal cancer, Cisplatin

\footnotetext{
* Correspondence: Fei-Fei.Liu@rmp.uhn.on.ca

'Princess Margaret Cancer Centre, University Health Network, Toronto,

Canada

Department of Medical Biophysics, University of Toronto, Toronto, Canada

Full list of author information is available at the end of the article
}

(c) The Author(s). 2020 Open Access This article is licensed under a Creative Commons Attribution 4.0 International License, which permits use, sharing, adaptation, distribution and reproduction in any medium or format, as long as you give appropriate credit to the original author(s) and the source, provide a link to the Creative Commons licence, and indicate if changes were made. The images or other third party material in this article are included in the article's Creative Commons licence, unless indicated otherwise in a credit line to the material. If material is not included in the article's Creative Commons licence and your intended use is not permitted by statutory regulation or exceeds the permitted use, you will need to obtain permission directly from the copyright holder. To view a copy of this licence, visit http://creativecommons.org/licenses/by/4.0/ The Creative Commons Public Domain Dedication waiver (http://creativecommons.org/publicdomain/zero/1.0/) applies to the data made available in this article, unless otherwise stated in a credit line to the data. 


\section{Background}

Nasopharyngeal carcinoma (NPC) patients presenting with locally advanced disease have a very modest overall survival (OS) rate of approximately $65 \%$ after 5 years [1-3]. Despite the use of intensity-modulated radiation therapy for this Epstein-Barr virus (EBV)-associated malignancy, 20-30\% of NPC patients will still succumb to distant metastasis (DM) [4]. Therapeutic options for such NPC patients are limited, and a primary clinical challenge is resistance to chemoradiation [5]. Concurrent chemotherapy (cisplatin/5-fluorouracil) with radiation therapy (RT) modestly improves OS, but can cause significant toxicity and death [4, 6-10].

Our group previously completed a global miRNA NPC patient sample profiling, discovering and validating a four-microRNA (miRNA) prognostic signature associated with risk for DM (low miR-34c, low miR-140, high miR-154, and high miR-449b) [11]. A subsequent study demonstrated that elevated levels of miR-449b were significantly associated with poor OS in patients receiving concurrent chemoradiotherapy [12]. MiR-449b overexpression in NPC was found to decrease transforming growth factor beta-induced (TGFBI), leading to an increase in transforming growth factor beta 1 (TGF $\beta 1$ ), TGF $\beta$ pathway activation, and cisplatin resistance [12].

TGF $\beta 1$ is a secreted protein involved in the regulation of many cellular mechanisms, such as metastasis formation, chemoresistance, epithelial-to-mesenchymal transition (EMT) [13, 14], and more recently, miRNA expression $[15,16]$. This latter process occurs via TGF 31 -mediated Smad activation whereby Smads bind to miRNA promoter regions that contain Smad-binding elements, as well as the Drosha complex [17]. Conversely, numerous miRNAs have been shown to negatively regulate TGF $\beta$ pathways [18].

TGF $\beta 1$ mediates the overexpression of SOX4, a member of the SOX (SRY-related HMG-box) family of transcription factors, which are known to be involved in developmental pathologies and cancer [19-22]. SOX4 dysregulation is involved in a myriad of cellular phenomena, such as the cell cycle, apoptosis, response to chemoradiation, metastasis development, and EMT [19, 23-27]. It is highly expressed in prostate [28], glioma [29], gastric [30], and breast cancers [27, 31], and its elevated expression, in turn has been associated with worse survival in prostate [32], gastric [30, 33], and colon cancers [34], as well as NPC [35]. The opposite however, has also been observed in several other malignancies, suggesting that the involvement of SOX4 may be context-dependent [36, 37].

Another component of the four-miRNA DM signature is miR-34c, which was only compared to other miRNAs within NPC, but not assessed in healthy individuals [11]. Other groups have shown miR-34c downregulation in NPC compared to normal tissue [38, 39], which has also been demonstrated in several other cancers [40-43]. MiR-34c is a member of the miR-34 family, which is composed of three pro-apoptotic members: miR-34a, miR-34b, and miR-34c, all of which have been described as transcriptional targets of p53 [44]. MiR-34a is located on chromosome $1 \mathrm{p} 36$, whereas $\mathrm{miR}-34 \mathrm{~b} / \mathrm{c}$ are located on chromosome 11q23 [45]. While extensive research has been conducted on miR-34a [46], identifying its role in chemosensitivity $[47,48]$, prevention of metastasis formation [49-52], and reverting EMT [53, 54], there is a paucity of information regarding miR-34c.

In this current study, the biological mechanisms and effects of miR-34c downregulation were investigated. The data suggest that this downregulation is caused by TGF $\beta 1$, which leads to SOX4 disinhibition, which in turn promotes EMT and cisplatin resistance in NPC two features that contribute to the formation of DM.

\section{Methods}

\section{Patient samples}

In compliance with the Institutional Research Ethics Board at the University Health Network (UHN), all patients provided written consent for the use of their tissues in this study. Diagnostic formalin-fixed paraffinembedded (FFPE) blocks were obtained from NPC patients $(n=246)$ treated at the Princess Margaret Cancer Center (PMCC) between 1993 to 2009, as previously described [11]. FFPE tissues from patients who underwent quadroscopy and were not diagnosed with NPC $(n=17)$ were used as normal nasopharyngeal epithelial tissues.

\section{NanoString analysis}

RNA was isolated using the Recover All Total Nucleic Acid Isolation Kit for FFPE (Ambion, Austin, TX, USA). Total RNA (200 ng) was assayed using the nCounter $\mathrm{Hu}$ man miRNA Assay v1.0 (Nanostring; 734 unique human and viral miRNAs). Please note that this experiment was also used for a previous study. Full analyses and protocols can be found in Bruce et al. [11].

\section{Cell culture}

The EBV-positive NPC cell line C666-1, the nontumorigenic human nasopharyngeal cell lines NP69 (SV40-immortalized) and NP460 (hTert-immortalized), and HEK $293 \mathrm{~T}$ cells were cultured as previously described [12]. NP69 and NP460 cell lines were generated by SW Tsao's group $[55,56]$ and served as "normal" cells throughout this study. Every new batch of cells underwent mycoplasma testing and STR analyses [12]. C666-1, NP69 and NP460 cells were used for gain- and loss-of-function assays; HEK $293 \mathrm{~T}$ (ATCC CRL-32 L) cells were used for lentiviral generation and luciferase assays. 


\section{Compound treatments}

SB431542 (\#S1067, SelleckChem, Houston, TX, USA), a TGF $\beta$ receptor I (TGF $\beta R 1$, also known as ALK5) inhibitor, was used as indicated. Human TGF $\beta 1$ (\#8915; Cell Signaling, Danvers, MA, USA) was used where indicated after overnight starvation of cells in Minimum Essential Media (MEM) supplemented with 0.5\% FBS.

\section{Transfection}

Polyplus-transfection JetPRIME (Graffenstaden, France) was used for transfection of C666-1, NP69, NP460, and HEK 293 T cells, according to manufacturer's specifications. C666-1, NP69, and NP460 cells were transfected with pre-miR-34c or pre-miR negative control $(20 \mathrm{nM}$ and $50 \mathrm{nM}$, Ambion, Austin, TX, USA).

\section{Lentiviral transduction}

Lentiviral transduction was used to generate stable cell lines as previously described [12]. pLV-miRNA-34c (Biosettia, San Diego, CA, USA), pLV-miR-34c-lockers (Biosettia, San Diego, CA, USA), and their respective control vectors were used. All stable cell lines were generated for the purpose of this work.

\section{Quantitative real-time PCR (qRT-PCR)}

The Total RNA Purification Kit (Norgen Biotek, Thorold, ON, Canada) was used for both mRNA and miRNA isolation. Reverse-transcription of total RNA $(1 \mu \mathrm{g})$ was performed using the iScript cDNA Synthesis Kit (BioRad, Hercules, CA, USA). qRT-PCR was performed using SYBR Green (Roche, Basel, Switzerland) and the primers are listed in Table 1. mRNA expression was normalized to the average expression of two housekeeping genes ( $\beta$-actin and GAPDH, as in [12]) and melting curves were generated for each experiment. MiRNA levels were assessed using the TaqMan MicroRNA Assay, and processed according to manufacturer's instructions (Applied Biosystem, Foster City, CA, USA). RNU44 and RNU48 were used to normalize miR-34c expression [57, 58]. Relative expression was calculated using the $2^{-\Delta \Delta C t}$ method [59].

\section{Western blot}

Immunoprecipitation buffer $(150 \mathrm{mM} \quad \mathrm{NaCl}, 5 \mathrm{mM}$ EDTA, 50 mM Hepes pH 7.6, 1-2\% Nonidet P-40; with protease inhibitor cocktail, Roche), was used for protein extraction. Electrophoresis was performed with Bolt 420\% Gels (Life Technologies, Carlsbad, CA, USA).

The Epithelial-Mesenchymal Transition Antibody Sampler Kit (Cell Signaling; \#9782; 1/1000 each), antiTGF $\beta 1$ (Cell Signaling; \#3711; $1 / 1000$ ), and anti- $\beta$-actin (Sigma: 1/5000) antibodies were used. The SuperSignal West Femto ECL (Pierce, \#34095, Thermo Scientific, Waltham, MA, USA) was used for ZEB1, CDH1 and

Table 1 Oligonucleotides used for qRT-PCR

\begin{tabular}{|c|c|c|}
\hline Gene & Forward Primer ( $5^{\prime}$ to $3^{\prime}$ ) & Reverse Primer ( $5^{\prime}$ to $3^{\prime}$ ) \\
\hline$\beta$-actin & AGAGCTACGAGCTGCCTGAC & AGCACTGTGTTGGCGTACAG \\
\hline ARID5A & ACCAGATGATGCCAGGAAAG & GAGCTTCTTTTTGGCCAGTG \\
\hline BAX & GGGTGGTTGCCCTITTCTACT & CCCGGAGGAAGTCCAGTGTC \\
\hline BIK & AAGACCCCTCTCCAGAGACAT & CAAGAACCTCCATGGTCGGG \\
\hline CCL22 & ACTGCACTCCTGGTTGTCCT & CGGCACAGATCTCCTTATCC \\
\hline GAPDH & TGTTGCCATCAATGACCCCTT & CTCCACGACGTACTCAGCG \\
\hline LITAF & TCGGTTCCAGGACCTTACCA & GGAGGATTCATGCCCTTCCC \\
\hline MARCKS & CCCAGTTCTCCAAGACCGC & CTGTCCGTTCGCTTTGGAAG \\
\hline MR1 & GACTCGCACCCTATCACCAC & CGAGGTTCTCTGCCATCCAT \\
\hline NFKBIA & GAAGTGATCCGCCAGGTGAA & CTGCTCACAGGCAAGGTGTA \\
\hline NOTCH1 & TCCACCAGTTTGAATGGTCA & AGCTCATCATCTGGGACAGG \\
\hline PDE4B & GGAAAAATCCCAGGTTGGTT & AGTGGTGGTGAGGGACTITG \\
\hline PML & GGCAGAGGAACGCGTTGTGGT & GGCTGGATGACCACGCGGAA \\
\hline RANGAP1 & TCAAGAGCTCAGCCTGCTTC & TTCCGGTGACATTCGGTCAG \\
\hline RBM4 & CTTGAGGTGGGATGTGTGTG & GCAGGAGAGGAAAGGAAAGG \\
\hline RNF24 & TGAGTTGGGGATTTGTCCAT & TACTTTGCGAACTTCCAGCC \\
\hline SOX2 & GCTACAGCATGATGCAGGACCA & TCTGCGAGCTGGTCATGGAGTT \\
\hline SOX4 & CCAAATCTITTGGGGACTIIT & CTGGCCCCTCAACTCCTC \\
\hline TGIF2 & TGAAGATCCTCCGGGACTGG & CAGCACTGACAGGTTGGTCT \\
\hline TRIO & AGCACACCTGGACCTAAAGC & GCACTCCAACACTCCACGTA \\
\hline
\end{tabular}


ZO-1 detection. Pierce ECL (\#32209) was used to detect all other proteins.

\section{RNA sequencing (RNA-Seq) and data analysis}

RNA from our cohort of FFPE samples was isolated (200 ng/sample), processed (Ribo-Zero Gold rRNA Removal Kit (Illumina, San Diego, CA, USA)), and sequenced as previously described (as in the NanoString section of [11]). A subset of these samples $(n=53)$ was processed for RNA-seq. Library preparation was performed using the TruSeq Stranded Total RNA Sample Prep Kit (Illumina, San Diego, CA, USA). Sequencing was conducted on the Illumina HiSeq 2000 to $>100$ million paired-end $100 \mathrm{bp}$ reads. STAR (v2.4.2a) was used to align the reads [60], and RSEM (v1.2.21) was used to summarize expression values [61].

Luciferase reporter assay for MiR-34c/SOX4 target activity MiR-34c was predicted to target the wild-type (WT) 3'untranslated region (3'UTR) of SOX4 in silico. This region was inserted into the pMIR-REPORT vector (Ambion). JetPRIME was used to reverse transfect HEK $293 \mathrm{~T}$ cells with pre-miR-control or pre-miR-34c. Twenty-four hours later, JetPRIME was used to cotransfect pRL-SV Renilla vector (Promega, Madison, WI, USA) with either pMIR-SOX4 3'UTR WT (CTAGTG CTCAGCTCAAGTTCACTGCCTGTCAGAT) or pMIR-SOX4 3'UTR Mutant (CTAGTGCTCAGCTC AAGTTTCTGTAAAGTCAGAT). The Dual-Luciferase Reporter Assay (Promega) was used to measure luciferase activity $24 \mathrm{~h}$ post-transfection.

\section{Cell viability assays}

Stable cell lines generated from C666-1, NP69 and NP460 cells were seeded in 96-well plates (2000 cells/ well). After 1 day, they were exposed to decreasing concentrations of cisplatin (CDDP) for $72 \mathrm{~h}$ as indicated in the figures. Dose-response curves for cisplatin were determined through treatment using two-fold serial dilutions starting from $12.5 \mu \mathrm{g} / \mathrm{mL}$ (which induced 90\% cell death in NP69/NP460 cells after $72 \mathrm{~h}$ of treatment). Cell viability was assessed using the ATPlite 1 Step Luminescence Assay System (PerkinElmer, Waltham, MA, USA).

\section{Immunohistochemistry (IHC)}

Sections from FFPE blocks were subject to IHC using microwave antigen retrieval. Citric acid $(0.01 \mathrm{M}, \mathrm{pH} 6.0)$ and the LSAB+ System-HRP (Dako, Les Ulis, France) were used. Rabbit polyclonal anti-SOX4 (PA5-41442, lot\#SB2344261A, Invitrogen: 1/40) antibody was used, but omitted for negative control staining. Positive nuclear SOX4 localization was detected by light microscopy. The percentage of positive tumour cells was quantified by evaluating a total of at least 300 tumour cells from the three most densely staining fields (magnification $400 \times$ ). A final score was calculated as the product of the percentage of positive tumour cells and staining intensity $(0=$ negative; $1=$ weak; $2=$ moderate; $3=$ strong) as previously described [62]. No samples had an intensity score of 3 . All scoring was performed blinded to any knowledge of clinical or pathological parameters. Each section was scored at least twice.

\section{Statistical analyses}

All experiments were performed at least three times. In order to maintain independence between replicates, new frozen batches of cells were used each time. Data are presented as the mean \pm SEM. GraphPad Prism (GraphPad Software, San Diego, CA, USA) was used for statistical analyses. Intergroup statistical significance was determined using the ANOVA test, with the Bonferroni post-test (if applicable), or the Mann-Whitney $U$ test (socscistatistics.com).

\section{Results}

MiR-34c is downregulated by TGF $\beta 1$

In order to investigate the role of miR-34c downregulation in the validated prognostic signature for NPC DM [11], we first confirmed that miR-34c expression was significantly reduced in NPC diagnostic FFPE samples compared to normal nasopharyngeal tissues using previously generated NanoString data [11] (Fig. 1a). Cell line models were then assessed for miR-34c expression. EBV-positive NPC cell line C666-1 exhibited significantly lower levels of miR-34c compared to the two normal (immortalized) nasopharyngeal cell lines NP69 and NP460 (Fig. 1b), consistent with clinical observations.

We had previously demonstrated that miR-449b overexpression, another component of the validated prognostic DM signature [11], led to TGFBI mRNA degradation with subsequent TGF $\beta 1$ accumulation [12]. Given that TGF $\beta 1$ plays an important role in NPC progression [53, 63-68] and in the regulation of miRNAs, particularly miR-34a [52], we sought to measure TGF $\beta 1$ in these cell lines. Indeed, C666-1 cells (which have high miR-449b expression [12]) expressed higher levels of active TGF 31 compared to either NP69 or NP460 cells (both of which have lower miR-449b expression [12]) (Fig. 1c). We therefore hypothesized that TGF $\beta 1$ could be regulating miR-34c in these cells. Treatment with recombinant TGF $\beta 1$ significantly reduced miR-34c expression in both NP69 and NP460 cells (Fig. 1d and e). Conversely, a TGF $\beta$ receptor 1 (TGFBR1) inhibitor (SB431542) increased miR-34c expression in C666-1 cells (Additional file 1: Figure S1A).

In order to confirm the association between increased miR-449b, increased TGF $\beta 1$, and decreased miR34c, 


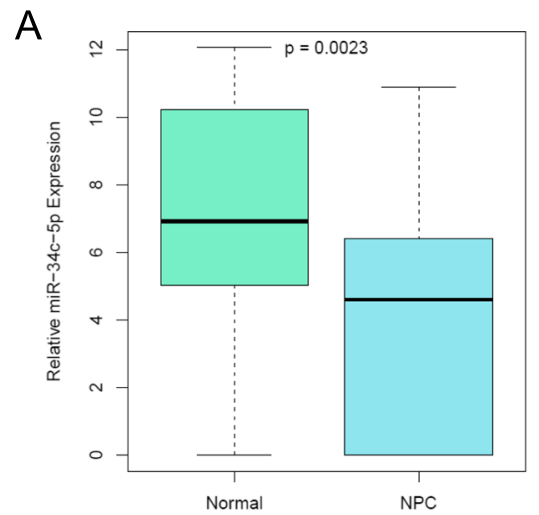

C

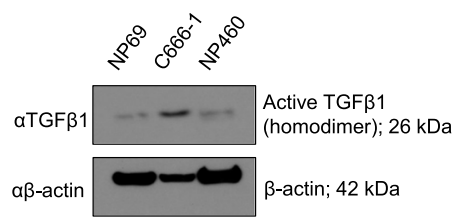

$E$

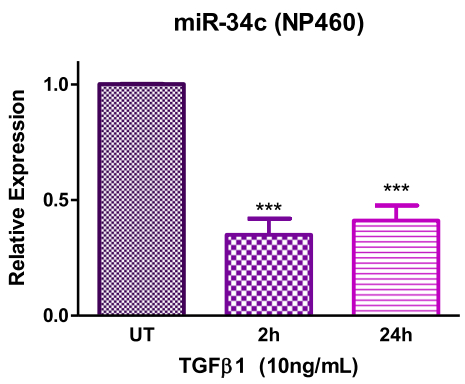

B

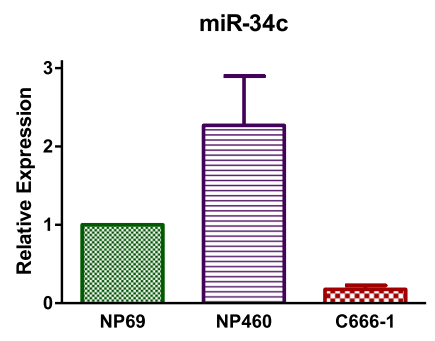

D

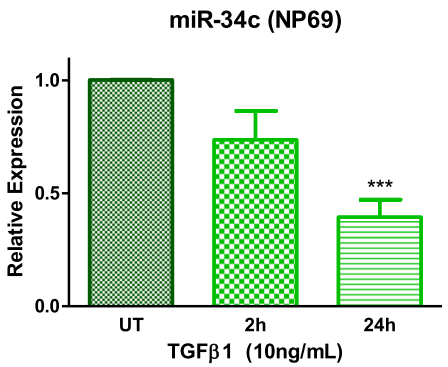

$\mathrm{F}$
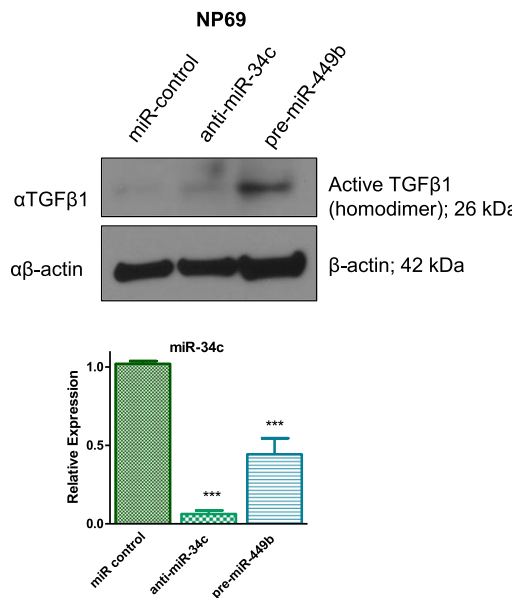

Fig. 1 MiR-34C is under-expressed in NPC and downregulated by TGF $\beta 1$. a Relative miR-34c expression in normal patients (not diagnosed with NPC) vs. NPC patients (using data from Bruce et al., 2014 [1 1]). b Relative expression (qRT-PCR) of miR-34c in NP69, NP460, and C666-1 cell lines, normalized to NP69 cells. c Whole cell lysate (WCL) Western blotting (WB) of NP69, C666-1, and NP460 cells using anti-TGF $\beta 1$ antibody (aTGF $\beta 1$ ), with anti- $\beta$-actin ( $a \beta$-actin) as the loading control. Full-length blots are presented in Additional file 5: Figure S5. (D and E) Relative miR-34c expression assessed by qRT-PCR after treatment with $10 \mathrm{ng} / \mathrm{mL}$ of recombinant TGF $\beta 1$ in NP69 (d) and NP460 (e) cells. UT = untreated. f WB performed on WCL of stably transfected NP69-miR-control, NP69-anti-miR-34c, and NP69-pre-miR-449b cells using anti-TGF $\beta 1$ antibody, with anti$\beta$-actin (a $\beta$-actin) as the loading control (top); corresponding relative miR-34c expression assessed by qRT-PCR (bottom). Full-length blots are presented in Additional file 5: Figure S5. The data are represented as the mean \pm SEM of at least three independent experiments. ${ }^{* * *} P<0.001$

NP69 cells stably expressing pre-miR-449b were compared to NP69 cells stably expressing miR-control or anti-miR-34c. NP69-pre-miR-449b cells expressed higher levels of active TGF $\beta 1$ protein compared to NP69-miR-control or NP69-anti-miR-34c cells (Fig. 1f, top); associated with a correspondingly lower expression of miR-34c compared to NP69-miR-control (Fig. 1f, bottom). Taken together, these data support the hypothesis that TGF $\beta 1$ decreases miR-34c expression, although the mechanism of regulation remains unknown.

\section{MiR-34c directly downregulates SOX4}

In order to identify miR-34c target candidates, 17 genes at the intersection between computationally predicted 
targets and genes upregulated in patient NPC samples [69] were examined (Fig. 2a). Using qRT-PCR, 6 of the 17 genes were observed to be upregulated in C666-1 (low miR-34c) compared to NP69 and NP460 cells (high
miR-34c) (Additional file 1: Figure S1B and C). These genes were then assessed for response to transient miR34c overexpression (pre-miR-34c transfection) (Fig. 2b for the 6 genes; Additional file 2: Figure S2A for the

\section{A}

MiR-34c computationally predicted

targets

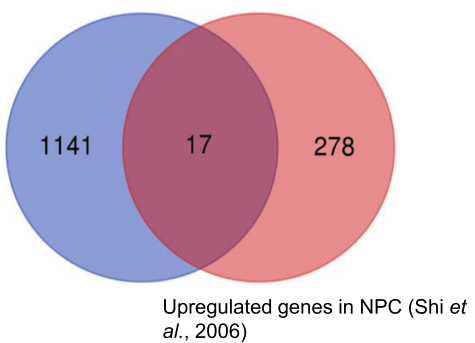

C

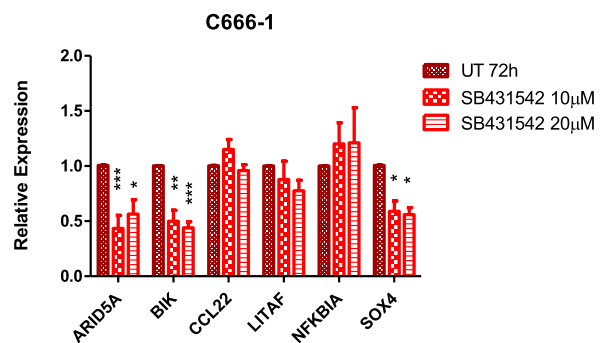

B

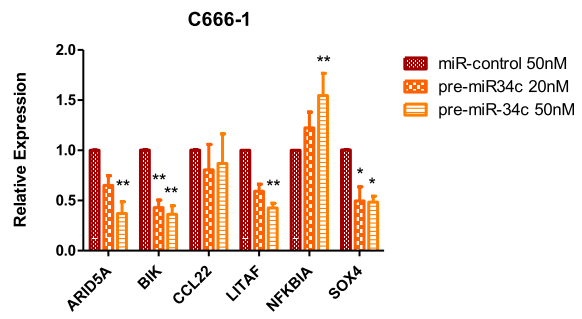

D

PMIR-3'UTR (HEK 293T)

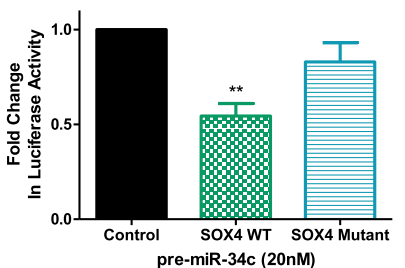

F All Patients

E
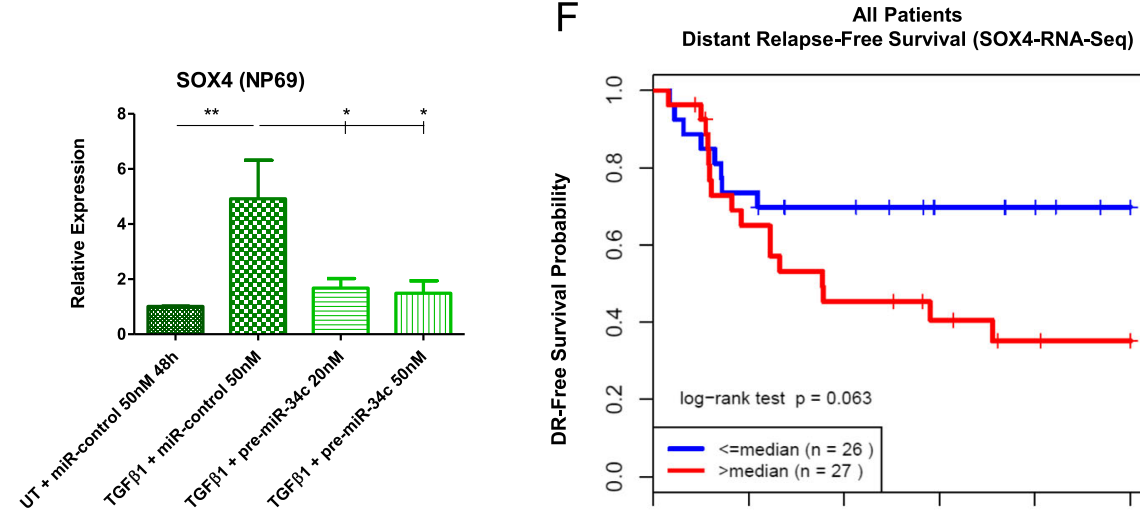

Fig. 2 MiR-34c inhibits SOX4 expression. a Evaluation of miR-34c targets: the Venn diagram was generated by combining miRWalk-predicted miR34c targets and the upregulated NPC genes from Shi et al., 2006 [69] using the online tool at www.bioinformatics.psb.ugent.be/webtools/Venn. b and $\mathbf{c}$ qRT-PCR of genes highly expressed in C666-1 cells compared to NP69/NP460 cells. b C666-1 cells were transiently transfected with premiR-34c (20 or 50 nM) for 72 h. c C666-1 cells were treated with SB431542 (10 or $20 \mu \mathrm{M}$ ) for 72 h. d Relative luciferase activity after transient transfection with pre-miR-34c (20 nM) for 48 h, followed by co-transfection with Renilla plasmid (100 ng) and either pMIR-SOX4 3'UTR Wildtype (WT) $(150 \mathrm{ng})$ or PMIR-SOX4 3'UTR Mutant (150 ng) for $24 \mathrm{~h}$. e qRT-PCR for SOX4 in NP69 cells transiently transfected with miR-control (50 nM), or pre-miR-34c (20 or $50 \mathrm{nM}$ ) for $72 \mathrm{~h}$; $8 \mathrm{~h}$ after transfection, the media was changed to MEM $0.5 \%$ FBS; the following morning, cells were treated with recombinant TGFB1 (10 ng/mL) for $48 \mathrm{~h}$. f Kaplan-Meier plot of DRFS for NPC patients $(n=53)$ dichotomized based on low ( $<\mathrm{median})$ vs. high (>median) SOX4 mRNA expression (median follow-up time $=6$ years). The data are represented as the mean \pm SEM of at least three independent experiments. ${ }^{*} P<0.05$; ${ }^{*} P<0.01$; ${ }^{* *} P<0.001$ 
other 11 genes), and TGF $\beta$ pathway inhibition using SB431542 (a TGFBR1 inhibitor, which also upregulates miR-34c) (Fig. 2c for the 6 genes; Additional file 2: Figure S2B for the remaining 11 genes) in C666-1 cells. As can be seen in Fig. 2b and c, elevated miR-34c conditions consistently and significantly downregulated ARID5A, BIK, and SOX4. Interestingly, BAX and PML were consistently and significantly upregulated (Additional file 2: Figure S2A and B), suggesting that they are not direct targets of miR-34c, but possibly further downstream or altered via a more complex mechanism.

The expression of the potential miR-34c targets was then determined through qRT-PCR on NP69 and NP460 cells transiently transfected with pre-miR-34c (Additional file 2: Figure S2C and D), as well as on NP69, NP460, and C666-1 cells stably expressing pre-miR-34c and anti-miR-34c (Additional file 2: Figure S2E, F, G, H, I and J). Together, these data show that only SOX4 was both significantly and inversely related to miR-34c in all tested cell line models. SOX4 is potentially important in the tumorigenesis of a number of different cancers (reviewed in [70]), including NPC [35, 71]. It is also known to be regulated by TGF $\beta 1$ [19], although its relationship with miR-34c remains to be investigated. Thus, we proceeded to interrogate the relationship between the TGF $\beta$ pathway, miR-34c, and SOX4.

First, miR-34c-mediated direct inhibition of SOX4 expression was confirmed using a luciferase reporter assay (Fig. 2d). The data were corroborated in NP69 cells, wherein TGF $\beta 1$ treatment significantly increased SOX4 expression, which was abrogated with miR-34c overexpression (Fig. 2e). Furthermore, RNA-seq performed on 53 diagnostic NPC biopsy samples revealed that patients with higher than median SOX4 transcript levels experienced a lower 10-year distant relapse-free survival (DRFS) compared to those with lower levels $(p=0.063)$ (Fig. 2f). Taken together, these data suggest that elevated TGF $\beta 1$ (via miR-449b upregulation (Fig. 1f) and consequent TGFBI degradation [12]) may lead to the downregulation of miR-34c, which directly upregulates SOX4 overexpression, possibly leading to an inferior 10-year DRFS, as seen in this dataset.

\section{MiR-34c regulates the SOX2-EMT Axis}

SOX4 has been characterized as a master regulator of EMT [25, 27], notably by upregulating SOX2 [19-22], a well-known mediator of tumour initiation and cancer stem cell maintenance [72-74]. We therefore hypothesized that miR-34c could affect EMT via SOX4 and SOX2. First, SOX2 was confirmed to be highly expressed in C666-1 cells (low miR-34c; high SOX4) compared to NP69 and NP460 cells (high miR-34c; low SOX4) (Fig. 3a). NP69 cells stably expressing SOX4 had a significant increase in SOX2 expression (Additional file 3:
Figure S3A), corroborating previous reports [19-22]. Moreover, downregulation of miR-34c in both NP69 and NP460 anti-miR-34c stable cell lines led to the significant upregulation of SOX2 (Fig. $3 \mathrm{~b}$ and c). The overexpression of miR-34c in C666-1 correspondingly decreased SOX2 transcript levels (Additional file 3: Figure S3B).

The expression of well-known EMT markers were then investigated. NP69 anti-miR-34c stable cells overexpressed SNAI1 (Snail), ZEB1, and CDH2, while underexpressing CLDN1 (Claudin-1), ZO-1, and CDH1 (Fig. 3d). Similar results were observed in NP460 anti-miR34c stable cells (Fig. 3e), supporting the role of miR-34c downregulation in the promotion of EMT in normal nasopharyngeal cell lines. C666-1 cells were not amenable to this gene expression analysis (ZEB1, CDH2, and CLDN1 are not expressed). However, TGFBR1 inhibition using SB431542 decreased SOX2 transcript expression in C666-1 cells (Fig. 3f). Taken together, the data show that high levels of TGF $\beta 1$ downregulate miR-34c, which directly leads to SOX4 overexpression and consequent SOX2 upregulation, promoting EMT in nasopharyngeal cells.

\section{TGFBR1 inhibition sensitizes C666-1 cells to cisplatin}

Our group previously demonstrated that miR-449b overexpression was associated with EMT and cisplatin sensitivity in NPC [12], with EMT being a well-described mediator of chemoresistance [75]. In this current study, miR-34c was found to be downregulated by TGF $\beta 1$ (Fig. 1 ), leading to EMT. On this basis, the potential involvement of miR-34c in cisplatin resistance was examined. Downregulation of miR-34c using anti-miR-34c significantly increased resistance to cisplatin in NP69, NP460, and C666-1 stable cell lines (Fig. 4a and b, Additional file 3: Figure S3C). Conversely, overexpression of miR$34 \mathrm{c}$ using pre-miR-34c increased cisplatin sensitivity in NP69, NP460, and C666-1 stable cell lines (Additional file 3: Figure S3D and E, Fig. 4c). Additionally, SB431542 treatment had a cytotoxic effect on C666-1 cells in a dose-dependent manner in vitro (Additional file 3: Figure S3F). The combination of SB431542 and cisplatin had an additive effect on the cell death of C666-1 cells (Fig. 4d). Finally, IHC performed on NPC biopsy samples from patients treated with chemoradiation $(n=25)$ demonstrated that lower SOX4 nuclear immunostaining was associated with a superior 10-year OS compared to patients with high SOX4 immunostaining ( $p=0.031$; Fig. $4 \mathrm{e}$, and Additional file 4: Figure S4). These data all support a role for the TGF 31 -miR34c-SOX4-SOX2 pathway in mediating cisplatin sensitivity in NPC.

In summary, miR-34c acts as a switch that controls EMT and chemoresistance in NPC. With TGF $\beta 1$ stimulation, miR-34c is repressed, directly leading to an 
A

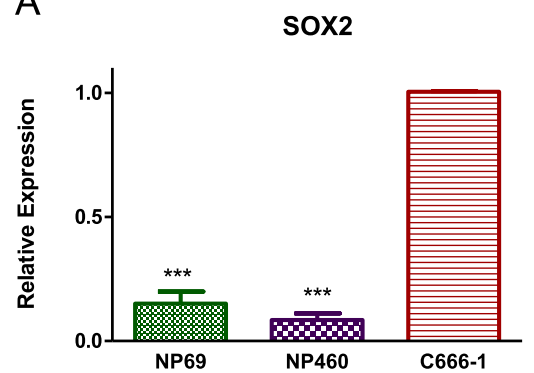

B

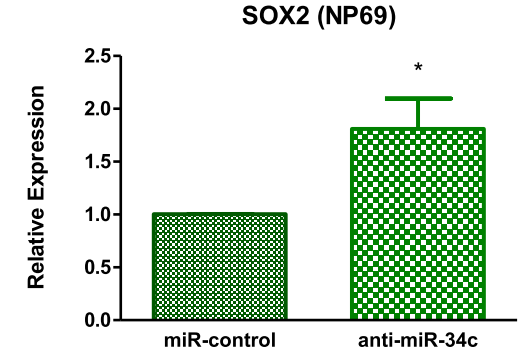

C SOX2 (NP460)

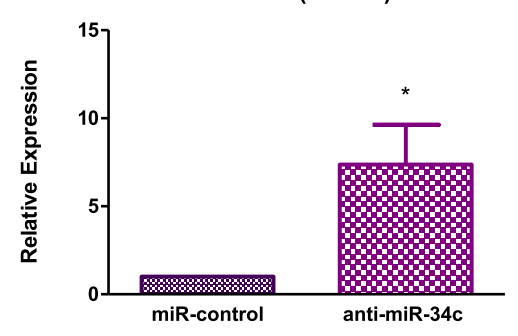

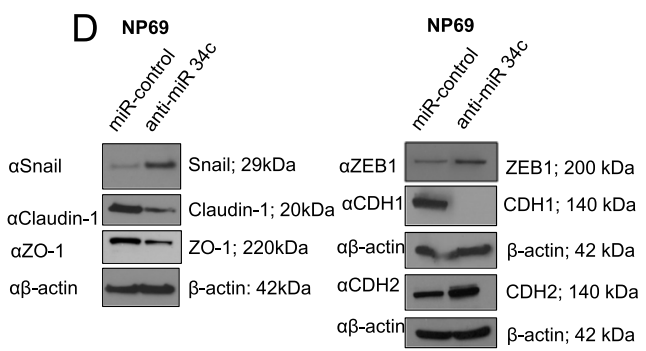
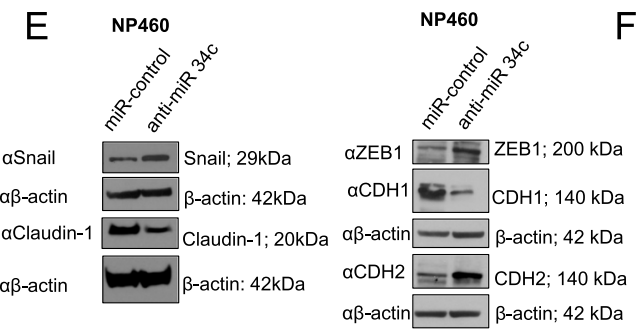

F

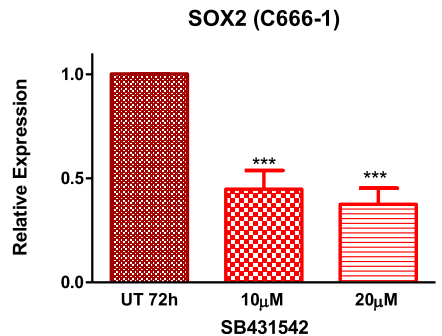

Fig. 3 MiR-34c regulates the SOX2-EMT axis in NPC cell lines. a, b and c Relative expression (qRT-PCR) of SOX2: a in NP69, NP460 and, C666-1 cell lines, normalized to C666-1 cells; $\mathbf{b}$ in NP69-anti-miR-34c stable cells and their control; $\mathbf{c}$ in NP460-anti-miR-34c stable cells and their control. $\mathbf{d}$ and $\mathbf{e}$ Western blots (WBs) were performed using anti-Snail (aSnail), anti-Claudin-1 (aClaudin-1), anti-ZO-1 (aZO-1), anti-ZEB1 (aZEB1), anti-CDH1 (aCDH1), anti-CDH2 (aCDH2), with anti- $\beta$-actin (aß-actin) as loading control. d WBs using NP69-anti-miR-34c stable cells and their control. Fulllength blots are presented in Additional file 6: Figure S6. (E) WBs using NP460-anti-miR-34c stable cells and their control. ZO-1 was undetectable in NP460 cell lines. Full-length blots are presented in Additional file 7: Figure S7. f Relative SOX2 expression assessed by qRT-PCR in C666-1 cells treated with SB431542 (10 or $20 \mu \mathrm{M})$. The data are expressed as the mean \pm SEM of at least three independent experiments. ${ }^{*} P<0.05$; *** $P<0.001$

increase in SOX4, which consequently upregulates SOX2, leading to EMT and cisplatin resistance in NPC (Fig. 4f).

\section{Discussion}

This study revealed a novel role of miR-34c in EMT and chemoresistance in NPC. Downregulation of miR-34c in our cellular model, caused at least partially by miR-449b overexpression and consequent TGF $\beta 1$ activity, resulted in SOX4 and SOX2 overexpression, which triggered EMT and cisplatin resistance (Fig. 4f). Concordantly, miR-34c overexpression sensitized NPC cells to cisplatin-a phenotype corroborated in other cancer types [76-79].

Interestingly, miR-34c and miR-449b belong to the same miRNA family, as their seed sequences are highly similar (reviewed in [80]). Despite having potentially overlapping predicted targets however, as illustrated in this study, they do not function in the same manner in every context. Our data do demonstrate a similar effect wherein both miR-449b and miR-34c lead to the same cellular outcome: EMT and cisplatin resistance. Further experiments would be required to unravel the roles of the other members of the miR-34/449 family in NPC. 
A

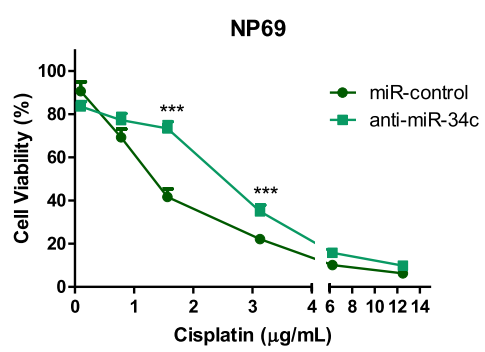

C

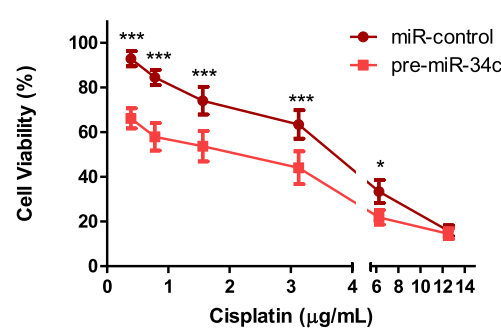

E

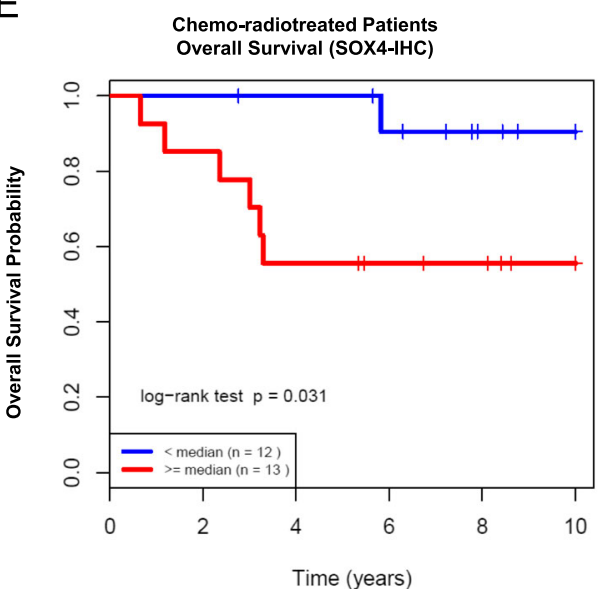

B

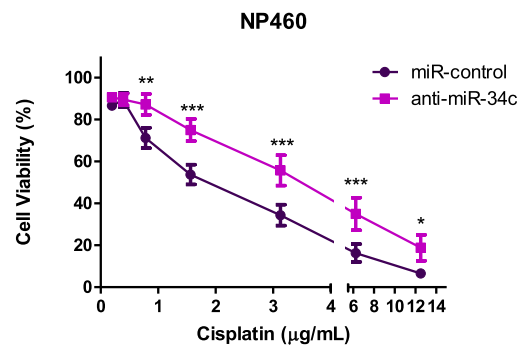

D

F
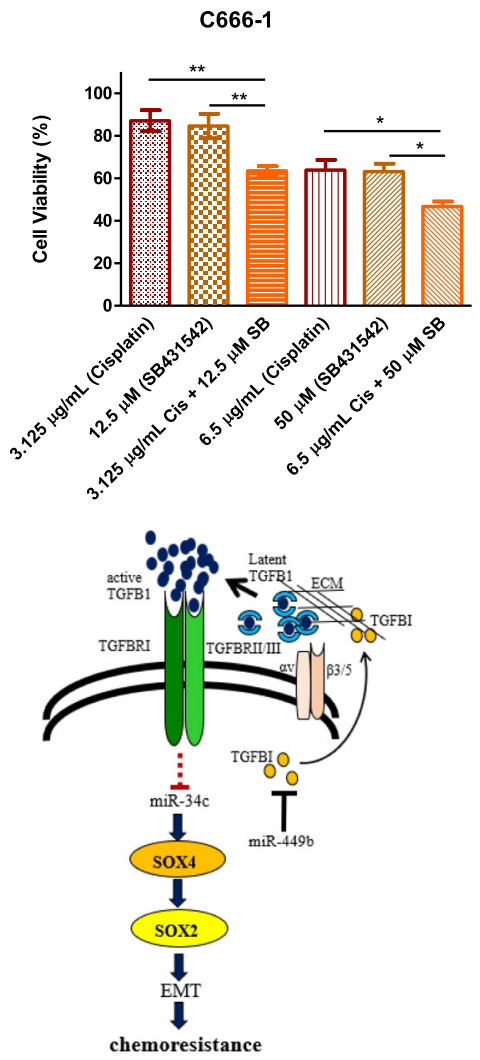

Fig. 4 MiR-34C and the TGF $\beta$ pathway are involved in cisplatin sensitivity in NPC cells. a to d Cell viability was assessed $72 \mathrm{~h}$ after cisplatin treatment using the ATPlite assay. a Stable NP69-anti-miR-34c (or control) cells. b Stable NP460-anti-miR-34c (or control) cells. c Stable C666-1pre-miR-34c (or control) cells. d C666-1 cells were treated simultaneously with combinations of cisplatin and SB431542 with varying doses. The data are represented as the mean \pm SEM of at least three independent experiments. ${ }^{*} P<0.05$; ${ }^{* *} P<0.01$; ${ }^{* *} P<0.001$. e Kaplan-Meier curve of OS based on low (<median) vs. high (>median) SOX4 expression (nuclear staining of tumour cells) using an anti-SOX4 polyclonal antibody in 25 NPC patients treated with chemoradiation (median follow-up time $=5$ years). $\mathbf{f}$ Proposed model for the miR-449-TGF $\beta 1$-miR-34c-SOX4 pathway [12]. The red dotted line indicates that the mechanism remains unknown

In NPC, miR-34c downregulation has been previously reported by several groups [11, 38, 39], but its mechanism of action has never been determined. This study elucidated a clear signaling pathway and provides data suggesting a myriad of other miR-34c effects. For example, our data demonstrated that miR-34c overexpression increased the expression of well-known pro-apoptotic genes, such as BAX [81] and PML [82]. Interestingly, the inhibition of PML nuclear bodies by the EBV protein EBNA1 has been described to contribute to tumorigenesis in NPC cells [83, 84]. MiR-34c has also been reported to suppress tumorigenesis through MET inhibition [38]. These and other miR-34c relationships remain to be further investigated in NPC.

Other miR-34 family members have been shown to be pro-apoptotic [44], with a liposome containing a miR34a mimic (MRX34) being developed and evaluated 
clinically as a therapeutic agent [85]. Additionally, while miR-34a regulates SOX2 expression through PAI-1 [86], its overexpression reverts EMT, which suppresses invasion in NPC [53] and enhances docetaxel sensitivity in prostate cancer [87].

There has been increasing evidence supporting a primary role for TGF $\beta$ pathway activation in NPC $[12,53$, 63, 65-67]. This current study demonstrated that miR$34 \mathrm{c}$ can be downregulated by TGF $\beta 1$, and that miR-449b overexpression can cause similar effects. Correspondingly, miR-449b upregulation and miR-34c downregulation were components of the four-miRNA prognostic signature for DM in NPC [11]. Cellular models mimicking these miRNA dysregulations display mesenchymal features and resistance to cisplatin, which are known contributors to disease recurrence and metastasis [12, 88, 89]. Furthermore, in C666- 1 cells, TGF $\beta$ pathway inhibition produced a similar gene expression profile to transient miR-34c overexpression (i.e. NOTCH1, TGIF2, BAX, and PML), suggesting a close relationship between TGF $\beta 1$ and miR-34c pathways. The relationship between these pathways and chemoresistance should be a potential avenue of investigation for future translational studies.

\section{Conclusion}

This study elucidates the novel role of miR-34c in EMT and cisplatin resistance. TGF $\beta 1$ negatively regulates miR-34c, which in turn increases the expression of SOX4 and SOX2, mediators of EMT triggering leading to cisplatin resistance (Fig. 4f). Correspondingly, miR$34 \mathrm{c}$ overexpression and TGF $\beta$ pathway inhibition leads to cisplatin sensitivity in NPC, highlighting a potential therapeutic strategy for this complex disease.

\section{Supplementary information}

Supplementary information accompanies this paper at https://doi.org/10. 1186/s12885-020-07081-z.

Additional file 1: Figure S1. (A) Relative miR-34c expression assessed by qRT-PCR in C666-1 cells treated with SB431542 (10 or $20 \mu \mathrm{M}$ ) for $72 \mathrm{~h}$ compared to untreated cells (UT). (B and C) Relative expression of putative miR-34c targets assessed by qRT-PCR in NP69, NP460, and C666-1 cells, normalized to C666-1 cells. (B) Genes that are highly expressed in C666-1 (NPC) cells vs. NP69 and NP460 (normal nasopharyngeal) cells. (C) Genes with no significant differences in expression between C666-1 cells and NP69/NP460. Note that MARCKS and PML expression were significant only between C666-1 and NP460 cells. The data are represented as the mean \pm SEM of at least three independent experiments. ${ }^{*} P<0.05$; ${ }^{* *} P<$ $0.01 ; * * * P<0.001$.

Additional file 2: Figure S2. (A) Relative expression of putative miR-34c target genes after transient transfection with pre-miR-34c (20 or $50 \mathrm{nM}$; $72 \mathrm{~h}$ after transfection) in C666-1 cells. (B) Relative expression of putative miR-34c target genes after SB431542 treatment (10 or $20 \mu \mathrm{M} ; 72 \mathrm{~h}$ ) in C666-1 cells. (C to J) Relative expression of significantly dysregulated genes (ARID5A, BIK, LITAF, NFKBIA, SOX4, BAX, and PML) as assessed by qRT-PCR. (C) Gene expression after transient transfection with pre-miR$34 \mathrm{c}(20$ or $50 \mathrm{nM}$ ) in NP69 cells. (D) Gene expression after transient transfection with pre-miR-34c (20 or 50 nM) in NP460 cells. (E) Gene expression of NP69-anti-miR-34c stable cells. (F) Gene expression of NP69pre-miR-34c stable cells. (G) Gene expression of NP460-anti-miR-34c stable cells. (H) Gene expression of NP460-pre-miR-34c stable cells. (I) Gene expression of (666-1-anti-miR-34c stable cells. (J) Gene expression of C666-1-pre-miR-34c stable cells. The data are represented as the mean \pm SEM of at least three independent experiments. ${ }^{*} P<0.05$; ${ }^{* *} P<$ $0.01 ;{ }^{* * *} P<0.001$.

Additional file 3: Figure S3. (A) Relative SOX4 and SOX2 expression assessed by qRT-PCR in NP69 cells stably overexpressing SOX4. (B) Relative SOX2 expression assessed by qRT-PCR in C666-1 cells stably expressing pre-miR-34C. (C, D, and E) Cell viability was measured by ATPlite assay $72 \mathrm{~h}$ after cisplatin treatment: (C) Stable C666-1-anti-miR-34c (or control) cells. (D) Stable NP69-pre-miR-34c (or control) cells. (E) Stable NP460-premiR-34c (or control) cells. (F) Effect of SB431542 on C666-1 cell viability measured by ATPlite at $72 \mathrm{~h}$. The data are represented as the mean \pm SEM of at least three independent experiments. ${ }^{*} P<0.05$; ${ }^{* *} P<0.01$; ${ }^{* * *}$ $P<0.001$.

Additional file 4 Figure S4. $1 \mathrm{HC}$ was performed on NPC patient samples with an anti-SOX4 polyclonal antibody. Representative photomicrographs of SOX4 expression in the tumour nuclei of scores 0, 1, and 2 at 200X. No samples presented with a score of 3.

Additional file 5: Figure S5. Uncropped Western blots for Fig. 1c and f. Additional file 6: Figure S6. Uncropped Western blots for Fig. 3d. Additional file 7: Figure S7. Uncropped Western blots for Fig. 3e.

\section{Abbreviations}

3'UTR: 3' untranslated region; CDDP: Cisplatin; $\mathrm{CDH1}$ : E-cadherin; $\mathrm{CDH} 2$ : Ncadherin; CLDN1: Claudin-1; DM: Distant metastasis; DMEM: Dulbecco's Modified Eagle Media; DRFS: Distant relapse-free survival; EBV: Epstein-Barr virus; EMT: Epithelial-to-mesenchymal transition; FBS: Fetal bovine serum; FFPE: Formalin-fixed and paraffin-embedded; IHC: Immunohistochemistry; MEM: Minimum Essential Media; miRNA: microRNA; NPC: Nasopharyngeal carcinoma; OS: Overall survival; qRT-PCR: quantitative real-time PCR; RT: Radiation therapy; SOX: SRY-related HMG-box; TGF $\beta 1$ : Transforming growth factor beta 1; TGFBI: Transforming growth factor beta-induced; WCL: Whole Cell Lysate; WT: Wild type; ZEB1: Zinc finger E-box binding homeobox 1

\section{Acknowledgments}

Not applicable.

\section{Authors' contributions}

P.-A.B. and F.-F.L. designed experiments; P.-A.B., M.T., J.H.L., W.S., and V.P. performed experiments; J.P.B. performed bioinformatic analysis; S.W.T supplied wild-type human normal nasopharyngeal cell lines and data. P.-A.B., M.T., J.H.L., J.P.B., W.S., V.P., K.W.Y., and F.-F.L. analyzed the data; P.-A.B., K.W.Y., and F.-F.L. wrote the manuscript. All authors read and approved the manuscript.

\section{Funding}

This research was funded by: 1. The Canadian Institutes for Health Research (\#PJT - 153289); 2. The Peter and Shelagh Godsoe Chair in Radiation Medicine; 3. The Mariano Elia Chair in Head \& Neck Cancer Research; 4. The Campbell Family Institute for Cancer Research; 5. The Ministry of Health and Long-Term Care; and 6. The Princess Margaret Cancer Centre Head \& Neck Translational Program, with philanthropic funds from the Wharton Family, Joe's Team, and Gordon Tozer. Additional funding from the Health \& Medical Research Fund (Hong Kong; \#04151726) and the Research Grant Council (Hong Kong; C7027-16G).

The funding bodies did not influence the design, collection, analysis, or interpretation of the study. The funding bodies did not influence the writing of the manuscript.

\section{Availability of data and materials}

The datasets used and/or analysed during the current study are available from the corresponding author on reasonable request. 


\section{Ethics approval and consent to participate}

In compliance with the Institutional Research Ethics Board at the University Health Network (UHN), all patients provided written consent for the use of their tissues in this study.

\section{Consent for publication}

Not applicable.

\section{Competing interests}

The authors have no conflict of interest to disclose.

\section{Author details}

${ }^{1}$ Princess Margaret Cancer Centre, University Health Network, Toronto, Canada. ${ }^{2}$ Department of Medical Biophysics, University of Toronto, Toronto, Canada. ${ }^{3}$ LabEx DEVweCAN, Université de Lyon, F-69000 Lyon, France. ${ }^{4}$ School of Biomedical Sciences, Li Ka Shing Faculty of Medicine, University of Hong Kong, Hong Kong, China. ${ }^{5}$ Radiation Medicine Program, Princess Margaret Cancer Centre, University Health Network, 610 University Avenue, Toronto, Ontario M5G 2M9, Canada. ${ }^{6}$ Department of Radiation Oncology, University of Toronto, Toronto, Canada.

\section{Received: 20 August 2019 Accepted: 16 June 2020}

\section{Published online: 26 June 2020}

\section{References}

1. Raab-Traub N. Epstein-Barr virus and nasopharyngeal carcinoma. Semin Cancer Biol. 1992;3(5):297-307.

2. Raab-Traub N. Epstein-Barr virus in the pathogenesis of NPC. Semin Cancer Biol. 2002;12(6):431-41.

3. Lee AW, Tung SY, Chan AT, Chappell R, Fu YT, Lu TX, et al. A randomized trial on addition of concurrent-adjuvant chemotherapy and/or accelerated fractionation for locally-advanced nasopharyngeal carcinoma. Radiother Oncol. 2011;98(1):15-22.

4. Lee AW, Tung SY, Ngan RK, Chappell R, Chua DT, Lu TX, et al. Factors contributing to the efficacy of concurrent-adjuvant chemotherapy for locoregionally advanced nasopharyngeal carcinoma: combined analyses of NPC-9901 and NPC-9902 trials. Eur J Cancer. 2011;47(5):656-66.

5. Lee AW, Ma BB, Ng WT, Chan AT. Management of Nasopharyngeal Carcinoma: current practice and future perspective. J Clin Oncol. 2015; 33(29):3356-64.

6. Blanchard P, Lee A, Marguet S, Leclercq J, Ng WT, Ma J, et al. Chemotherapy and radiotherapy in nasopharyngeal carcinoma: an update of the MAC-NPC meta-analysis. Lancet Oncol. 2015;16(6):645-55.

7. Lee AW, Tung SY, Chua DT, Ngan RK, Chappell R, Tung R, et al. Randomized trial of radiotherapy plus concurrent-adjuvant chemotherapy vs radiotherapy alone for regionally advanced nasopharyngeal carcinoma. J Natl Cancer Inst. 2010;102(15):1188-98.

8. Frikha M, Auperin A, Tao Y, Elloumi F, Toumi N, Blanchard P, et al. A randomized trial of induction docetaxel-cisplatin-5FU followed by concomitant cisplatin-RT versus concomitant cisplatin-RT in nasopharyngeal carcinoma (GORTEC 2006-02). Ann Oncol. 2018;29(3):731-6.

9. Lee AW, Ng WT, Chan YH, Sze H, Chan C, Lam TH. The battle against nasopharyngeal cancer. Radiother Oncol. 2012;104(3):272-8.

10. Lee AW, Ng WT, Chan LL, Hung WM, Chan CC, Sze HC, et al. Evolution of treatment for nasopharyngeal cancer--success and setback in the intensitymodulated radiotherapy era. Radiother Oncol. 2014;110(3):377-84.

11. Bruce JP, Hui AB, Shi W, Perez-Ordonez B, Weinreb I, Xu W, et al. Identification of a microRNA signature associated with risk of distant metastasis in nasopharyngeal carcinoma. Oncotarget. 2015;6(6):4537-50.

12. Bissey PA, Law JH, Bruce JP, Shi W, Renoult A, Chua MLK, et al. Dysregulation of the MiR-449b target TGFBI alters the TGF $\beta$ pathway to induce cisplatin resistance in nasopharyngeal carcinoma. Oncogenesis. 2018;7(5):40.

13. Massagué J, Xi Q. TGF- $\beta$ control of stem cell differentiation genes. FEBS Lett. 2012:586(14):1953-8

14. Oshimori N, Oristian D, Fuchs E. TGF- $\beta$ promotes heterogeneity and drug resistance in squamous cell carcinoma. Cell. 2015:160(5):963-76.

15. Guo L, Zhang Y, Zhang L, Huang F, Li J, Wang S. MicroRNAs, TGF- $\beta$ signaling, and the inflammatory microenvironment in cancer. Tumour Biol. 2016;37(1):115-25
16. Chen W, Zhou S, Mao L, Zhang H, Sun D, Zhang J, et al. Crosstalk between TGF- $\beta$ signaling and miRNAs in breast cancer metastasis. Tumour Biol. 2016; 37(8):10011-9.

17. Hata A, Davis BN. Control of microRNA biogenesis by TGFbeta signaling pathway-a novel role of Smads in the nucleus. Cytokine Growth Factor Rev. 2009:20(5-6):517-21.

18. Suzuki HI. MicroRNA control of TGF- $\beta$ signaling. Int J Mol Sci. 2018;19(7): 1901.

19. Ikushima H, Todo T, Ino Y, Takahashi M, Miyazawa K, Miyazono K. Autocrine TGF-beta signaling maintains tumorigenicity of glioma-initiating cells through Sry-related HMG-box factors. Cell Stem Cell. 2009;5(5):504-14.

20. Ikushima H, Todo T, Ino Y, Takahashi M, Saito N, Miyazawa K, et al. Gliomainitiating cells retain their tumorigenicity through integration of the sox axis and Oct4 protein. J Biol Chem. 2011;286(48):41434-41.

21. Weina K, Wu H, Knappe N, Orouji E, Novak D, Bernhardt M, et al. TGF- $\beta$ induces SOX2 expression in a time-dependent manner in human melanoma cells. Pigment Cell Melanoma Res. 2016;29(4):453-8.

22. Liu Z, Kuang W, Zhou Q, Zhang Y. TGF- $\beta 1$ secreted by M2 phenotype macrophages enhances the stemness and migration of glioma cells via the SMAD2/3 signalling pathway. Int J Mol Med. 2018;42(6):3395-403.

23. Bilir B, Osunkoya AO, Wiles WG, Sannigrahi S, Lefebvre $V$, Metzger D, et al. SOX4 is essential for prostate tumorigenesis initiated by PTEN ablation. Cancer Res. 2016;76(5):1112-21.

24. Sun R, Jiang B, Qi H, Zhang X, Yang J, Duan J, et al. SOX4 contributes to the progression of cervical cancer and the resistance to the chemotherapeutic drug through ABCG2. Cell Death Dis. 2015;6:e1990.

25. Tiwari N, Tiwari VK, Waldmeier L, Balwierz PJ, Arnold P, Pachkov M, et al. Sox4 is a master regulator of epithelial-mesenchymal transition by controlling Ezh2 expression and epigenetic reprogramming. Cancer Cell. 2013:23(6):768-83.

26. Yoon TM, Kim SA, Cho WS, Lee DH, Lee JK, Park YL, et al. SOX4 expression is associated with treatment failure and chemoradioresistance in oral squamous cell carcinoma. BMC Cancer. 2015;15:888.

27. Zhang J, Liang Q, Lei Y, Yao M, Li L, Gao X, et al. SOX4 induces epithelialmesenchymal transition and contributes to breast cancer progression. Cancer Res. 2012;72(17):4597-608.

28. Liu P, Ramachandran S, Ali Seyed M, Scharer CD, Laycock N, Dalton WB, et al. Sex-determining region $Y$ box 4 is a transforming oncogene in human prostate cancer cells. Cancer Res. 2006;66(8):4011-9.

29. Han W, Hu P, Wu F, Wang S, Hu Y, Li S, et al. FHL3 links cell growth and selfrenewal by modulating SOX4 in glioma. Cell Death Differ. 2019;26:796-811.

30. Yuan X, Wang S, Liu M, Lu Z, Zhan Y, Wang W, et al. Histological and pathological assessment of miR-204 and SOX4 levels in gastric cancer patients. Biomed Res Int. 2017;2017:6894675.

31. Mehta GA, Parker JS, Silva GO, Hoadley KA, Perou CM, Gatza ML. Amplification of SOX4 promotes PI3K/Akt signaling in human breast cancer. Breast Cancer Res Treat. 2017:162(3):439-50.

32. Wang L, Zhang J, Yang X, Chang YW, Qi M, Zhou Z, et al. SOX4 is associated with poor prognosis in prostate cancer and promotes epithelial-mesenchymal transition in vitro. Prostate Cancer Prostatic Dis. 2013;16(4):301-7.

33. Fang CL, Hseu YC, Lin YF, Hung ST, Tai C, Uen YH, et al. Clinical and prognostic association of transcription factor SOX4 in gastric cancer. PLoS One. 2012:7(12):e52804.

34. Lin CM, Fang CL, Hseu YC, Chen CL, Wang JW, Hsu SL, et al. Clinical and prognostic implications of transcription factor SOX4 in patients with colon cancer. PLoS One. 2013;8(6):e67128.

35. Shi S, Cao X, Gu M, You B, Shan Y, You Y. Upregulated expression of SOX4 is associated with tumor growth and metastasis in nasopharyngeal carcinoma. Dis Markers. 2015;2015:658141.

36. Vervoort SJ, van Boxtel R, Coffer PJ. The role of SRY-related HMG box transcription factor 4 (SOX4) in tumorigenesis and metastasis: friend or foe? Oncogene. 2013;32(29):3397-409.

37. Vervoort SJ, de Jong OG, Roukens MG, Frederiks CL, Vermeulen JF, Lourenço AR, et al. Global transcriptional analysis identifies a novel role for SOX4 in tumor-induced angiogenesis. Elife. 2018;7:e27706.

38. Li YQ, Ren XY, He QM, Xu YF, Tang XR, Sun Y, et al. MiR-34c suppresses tumor growth and metastasis in nasopharyngeal carcinoma by targeting MET. Cell Death Dis. 2015:6:e1618.

39. Wang F, Lu J, Peng X, Wang J, Liu X, Chen $X$, et al. Integrated analysis of microRNA regulatory network in nasopharyngeal carcinoma with deep sequencing. J Exp Clin Cancer Res. 2016;35:17. 
40. Hagman Z, Larne O, Edsjö A, Bjartell A, Ehrnström RA, Ulmert D, et al. miR$34 \mathrm{C}$ is downregulated in prostate cancer and exerts tumor suppressive functions. Int J Cancer. 2010;127(12):2768-76.

41. Sousa LO, Sobral LM, Matsumoto CS, Saggioro FP, López RV, Panepucci RA, et al. Lymph node or perineural invasion is associated with low miR-15a, miR-34c and miR-199b levels in head and neck squamous cell carcinoma. BBA Clin. 2016;6:159-64.

42. Wang Z, Chen Z, Gao Y, Li N, Li B, Tan F, et al. DNA hypermethylation of microRNA-34b/c has prognostic value for stage I non-small cell lung cancer. Cancer Biol Ther. 2011;11(5):490-6.

43. Yang DQ, Zhou JD, Wang YX, Deng ZQ, Yang J, Yao DM, et al. Low miR-34c expression is associated with poor outcome in de novo acute myeloid leukemia. Int J Lab Hematol. 2017:39(1):42-50.

44. Misso G, Di Martino MT, De Rosa G, Faroogi AA, Lombardi A, Campani V, et al. Mir-34: a new weapon against cancer? Mol Ther Nucleic Acids. 2014:3:e194.

45. Hermeking $H$. The miR-34 family in cancer and apoptosis. Cell Death Differ. 2010;17(2):193-9.

46. Lacombe J, Zenhausern F. Emergence of miR-34a in radiation therapy. Crit Rev Oncol Hematol. 2017;109:69-78.

47. Wen D, Peng Y, Lin F, Singh RK, Mahato Rl. Micellar delivery of miR-34a modulator Rubone and paclitaxel in resistant prostate cancer. Cancer Res. 2017;77(12):3244-54

48. Zhang Q, Zhuang J, Deng Y, Yang L, Cao W, Chen W, et al. miR34a/GOLPH3 Axis abrogates urothelial bladder cancer Chemoresistance via reduced cancer Stemness. Theranostics. 2017;7(19):4777-90.

49. Adams BD, Wali VB, Cheng CJ, Inukai S, Booth CJ, Agarwal S, et al. miR-34a silences C-SRC to attenuate tumor growth in triple-negative breast cancer. Cancer Res. 2016;76(4):927-39.

50. Bayraktar R, Ivan C, Bayraktar E, Kanlikilicer P, Kabil NN, Kahraman N, et al. Dual suppressive effect of miR-34a on the FOXM1/eEF2-kinase Axis regulates triple-negative breast cancer growth and invasion. Clin Cancer Res. 2018:24(17):4225-41.

51. Liu C, Kelnar K, Liu B, Chen X, Calhoun-Davis T, Li H, et al. The microRNA miR-34a inhibits prostate cancer stem cells and metastasis by directly repressing CD44. Nat Med. 2011;17(2):211-5.

52. Yang $P$, Li QJ, Feng Y, Zhang Y, Markowitz GJ, Ning S, et al. TGF-ß-miR-34aCCL22 signaling-induced Treg cell recruitment promotes venous metastases of HBV-positive hepatocellular carcinoma. Cancer Cell. 2012;22(3):291-303.

53. Huang G, Du MY, Zhu H, Zhang N, Lu ZW, Qian LX, et al. MiRNA-34a reversed TGF- $\beta$-induced epithelial-mesenchymal transition via suppression of SMAD4 in NPC cells. Biomed Pharmacother. 2018;106:217-24.

54. Lin X, Lin BW, Chen XL, Zhang BL, Xiao XJ, Shi JS, et al. PAl-1/PIAS3/Stat3/ miR-34a forms a positive feedback loop to promote EMT-mediated metastasis through Stat3 signaling in non-small cell lung cancer. Biochem Biophys Res Commun. 2017:493(4):1464-70.

55. Tsao SW, Wang X, Liu Y, Cheung YC, Feng H, Zheng Z, et al. Establishment of two immortalized nasopharyngeal epithelial cell lines using SV40 large T and HPV16E6/E7 viral oncogenes. Biochim Biophys Acta. 2002;1590(1-3):150-8.

56. Li HM, Man C, Jin Y, Deng W, Yip YL, Feng HC, et al. Molecular and cytogenetic changes involved in the immortalization of nasopharyngeal epithelial cells by telomerase. Int J Cancer. 2006;119(7):1567-76.

57. Hui AB, Lenarduzzi M, Krushel T, Waldron L, Pintilie M, Shi W, et al. Comprehensive MicroRNA profiling for head and neck squamous cell carcinomas. Clin Cancer Res. 2010;16(4):1129-39.

58. Vojtechova Z, Sabol I, Salakova M, Smahelova J, Zavadil J, Turek L, et al. Comparison of the miRNA profiles in HPV-positive and HPV-negative tonsillar tumors and a model system of human keratinocyte clones. BMC Cancer. 2016;16:382.

59. Livak KJ, Schmittgen TD. Analysis of relative gene expression data using real-time quantitative PCR and the 2 (-Delta Delta C (T)) method. Methods. 2001;25(4):402-8

60. Dobin A, Davis CA, Schlesinger F, Drenkow J, Zaleski C, Jha S, et al. STAR ultrafast universal RNA-seq aligner. Bioinformatics. 2013;29(1):15-21.

61. Li B, Dewey CN. RSEM: accurate transcript quantification from RNA-Seq data with or without a reference genome. BMC Bioinform. 2011;12:323.

62. Shi W, Pataki I, MacMillan C, Pintilie M, Payne D, O'Sullivan B, et al. Molecular pathology parameters in human nasopharyngeal carcinoma. Cancer. 2002; 94(7):1997-2006

63. Cao S, Cui Y, Xiao H, Mai M, Wang C, Xie S, et al. Upregulation of flotillin-1 promotes invasion and metastasis by activating TGF- $\beta$ signaling in nasopharyngeal carcinoma. Oncotarget. 2016;7(4):4252-64.
64. Tan EL, Selvaratnam G, Kananathan R, Sam CK. Quantification of Epstein-Barr virus DNA load, interleukin-6, interleukin-10, transforming growth factorbeta1 and stem cell factor in plasma of patients with nasopharyngeal carcinoma. BMC Cancer. 2006;6:227.

65. Velapasamy S, Dawson CW, Young LS, Paterson IC, Yap LF. The dynamic roles of TGF- $\beta$ Signalling in EBV-associated cancers. Cancers (Basel). 2018; 10(8):247.

66. Xu J, Menezes J, Prasad U, Ahmad A. Elevated serum levels of transforming growth factor beta1 in Epstein-Barr virus-associated nasopharyngeal carcinoma patients. Int J Cancer. 1999;84(4):396-9.

67. Zhao L, Lin L, Pan C, Shi M, Liao Y, Bin J, et al. Flotillin-2 promotes nasopharyngeal carcinoma metastasis and is necessary for the epithelialmesenchymal transition induced by transforming growth factor- $\beta$. Oncotarget. 2015;6(12):9781-93.

68. Zou G, Ren B, Liu Y, Fu Y, Chen P, Li X, et al. Inhibin B suppresses anoikis resistance and migration through the transforming growth factor $\beta$ signaling pathway in nasopharyngeal carcinoma. Cancer Sci. 2018;109(11): 3416-27.

69. Shi W, Bastianutto C, Li A, Perez-Ordonez B, Ng R, Chow KY, et al. Multiple dysregulated pathways in nasopharyngeal carcinoma revealed by gene expression profiling. Int J Cancer. 2006;119(10):2467-75.

70. Chen J, Ju HL, Yuan XY, Wang TJ, Lai BQ. SOX4 is a potential prognostic factor in human cancers: a systematic review and meta-analysis. Clin Transl Oncol. 2016;18(1):65-72.

71. Jiang C, Wang H, Zhou L, Jiang T, Xu Y, Xia L. MicroRNA-212 inhibits the metastasis of nasopharyngeal carcinoma by targeting SOX4. Oncol Rep. 2017;38(1):82-8.

72. Boumahdi S, Driessens G, Lapouge G, Rorive S, Nassar D, Le Mercier M, et al. SOX2 controls tumour initiation and cancer stem-cell functions in squamous-cell carcinoma. Nature. 2014;511(7508):246-50.

73. Favaro R, Appolloni I, Pellegatta S, Sanga AB, Pagella P, Gambini E, et al. Sox2 is required to maintain cancer stem cells in a mouse model of highgrade oligodendroglioma. Cancer Res. 2014;74(6):1833-44.

74. Kim BR, Coyaud E, Laurent EMN, St-Germain J, Van de Laar E, Tsao MS, et al. Identification of the SOX2 Interactome by BiolD reveals EP300 as a mediator of SOX2-dependent squamous differentiation and lung squamous cell carcinoma growth. Mol Cell Proteomics. 2017;16(10):1864-88.

75. Singh A, Settleman J. EMT, cancer stem cells and drug resistance: an emerging axis of evil in the war on cancer. Oncogene. 2010;29(34):4741-51.

76. Hu Y, Yang Q, Wang L, Wang S, Sun F, Xu D, et al. Knockdown of the oncogene IncRNA NEAT1 restores the availability of miR-34c and improves the sensitivity to cisplatin in osteosarcoma. Biosci Rep. 2018;38(3): BSR20180375.

77. Xiao S, Li Y, Pan Q, Ye M, He S, Tian Q, et al. MiR-34C/SOX9 axis regulates the chemoresistance of ovarian cancer cell to cisplatin-based chemotherapy. J Cell Biochem. 2018;120(3):2940-53.

78. Tung SL, Huang WC, Hsu FC, Yang ZP, Jang TH, Chang JW, et al. miRNA34c-5p inhibits amphiregulin-induced ovarian cancer stemness and drug resistance via downregulation of the AREG-EGFR-ERK pathway. Oncogenesis. 2017;6(5):e326.

79. Wu H, Huang M, Lu M, Zhu W, Shu Y, Cao P, et al. Regulation of microtubule-associated protein tau (MAPT) by miR-34c-5p determines the chemosensitivity of gastric cancer to paclitaxel. Cancer Chemother Pharmacol. 2013;71(5):1159-71.

80. Lv J, Zhang Z, Pan L, Zhang Y. MicroRNA-34/449 family and viral infections. Virus Res. 2019;260:1-6.

81. Korsmeyer SJ, Wei MC, Saito M, Weiler S, Oh KJ, Schlesinger PH. Pro-apoptotic cascade activates BID, which oligomerizes BAK or BAX into pores that result in the release of cytochrome c. Cell Death Differ. 2000;7(12):1166-73.

82. Pinton P, Giorgi C, Pandolfi PP. The role of PML in the control of apoptotic cell fate: a new key player at ER-mitochondria sites. Cell Death Differ. 2011; 18(9):1450-6.

83. Sivachandran N, Sarkari F, Frappier L. Epstein-Barr nuclear antigen 1 contributes to nasopharyngeal carcinoma through disruption of PML nuclear bodies. PLoS Pathog. 2008;4(10):e1000170.

84. Sivachandran N, Cao JY, Frappier L. Epstein-Barr virus nuclear antigen 1 hijacks the host kinase CK2 to disrupt PML nuclear bodies. J Virol. 2010; 84(21):11113-23.

85. Beg MS, Brenner AJ, Sachdev J, Borad M, Kang YK, Stoudemire J, et al. Phase I study of MRX34, a liposomal miR-34a mimic, administered twice weekly in patients with advanced solid tumors. Investig New Drugs. 2017;35(2):180-8. 
86. Zhang Y, Pan Y, Xie C. miR-34a exerts as a key regulator in the dedifferentiation of osteosarcoma via PAl-1-Sox2 axis. Cell Death Dis. 2018;9(7):777.

87. Zhang G, Tian X, Li Y, Wang Z, Li X, Zhu C. miR-27b and miR-34a enhance docetaxel sensitivity of prostate cancer cells through inhibiting epithelial-tomesenchymal transition by targeting ZEB1. Biomed Pharmacother. 2018;97:736-44.

88. Ghosh RD, Ghuwalewala S, Das P, Mandloi S, Alam SK, Chakraborty J, et al. MicroRNA profiling of cisplatin-resistant oral squamous cell carcinoma cell lines enriched with cancer-stem-cell-like and epithelial-mesenchymal transition-type features. Sci Rep. 2016;6:23932.

89. Yang CX, Sedhom W, Song J, Lu SL. The role of MicroRNAs in recurrence and metastasis of head and neck squamous cell carcinoma. Cancers (Basel). 2019;11(3):395

\section{Publisher's Note}

Springer Nature remains neutral with regard to jurisdictional claims in published maps and institutional affiliations.

Ready to submit your research? Choose BMC and benefit from:

- fast, convenient online submission

- thorough peer review by experienced researchers in your field

- rapid publication on acceptance

- support for research data, including large and complex data types

- gold Open Access which fosters wider collaboration and increased citations

- maximum visibility for your research: over $100 \mathrm{M}$ website views per year

At BMC, research is always in progress.

Learn more biomedcentral.com/submissions 